\title{
Prevention of Early Postoperative Deep Vein Thrombosis by Passive Exercise of Leg During Surgery
}

\author{
S. SABRI, V. C. ROBERTS, L. T. COTTON
}

British Medical fournal, 1971, 3, 82-83

\section{Summary}

A clinical trial assessed the effect of passive exercise of the lower limb during surgery on the incidence of early postoperative deep vein thrombosis. Thrombosis was diagnosed by means of the ${ }^{125} \mathrm{I}$-fibrinogen uptake test. Passive exercise of the lower limb during the operation was achieved by using a motorized foot mover designed for use on supine subjects, and by pedalling only one leg each patient acted as his own control.

In a sequential statistical analysis, 47 patients were required to reach the $5 \%$ level of significance. Thrombosis was detected in 11 control (unpedalled) legs alone, and in only one pedalled leg alone. Two patients developed thrombosis bilaterally. The investigation shows that the incidence of early thrombosis in legs which were exercised during surgery was reduced by $77 \%$.

\section{Introduction}

Slowing of the flow of blood in the legs has been held to be a cause of deep vein thrombosis ever since Virchow (1856) described his triad of factors causing thrombosis. Clark and Cotton (1968) showed that a dramatic fall in venous flow occurs during the induction of anaesthesia and during the course of an operation. We have found that passive exercise of the leg during surgery increased the mean femoral arterial flow (Sabri et al., 1971) as well as the pulsatility of the femoral venous flow (Roberts et al., 1971).

The discovery of the ${ }^{125} \mathrm{I}$-fibrinogen test for venous thrombosis by Atkins and Hawkins (1965) provided a precise test by which methods of prophylaxis may be assessed. Flanc et al. (1968), using this test, showed that over $35 \%$ of surgical patients aged 40 or more years develop post-operative thombosis, but in only half does it become obvious clinically.

Eighty per cent. of the cases of postoperative thrombosis occur during the first three days and the remaining $20 \%$ between the fourth and sixth days (Browse and Negus, 1970). Postoperative thrombosis seems to be a biphasic phenomenon, the first phase being initiated by venous stasis during the operation and soon after it, the second phase being initiated by platelet adhesiveness which has been shown to reach a maximum on the third day (Dhall et al., 1968).

It is these early thromboses that might be prevented by passive exercise of the legs during operation. Accordingly, we have designed a clinical trial to evaluate the effect of passive exercise of the leg during surgery on the incidence of thrombosis as detected by the ${ }^{125}$ I-fibrinogen test.

\footnotetext{
Department of Biomedical Engineering, King's College Hospital Medical School, London S.E.5

S. SABRI, M.B., PH.D., Honorary Senior Surgical Registrar/Lecturer

V. C. ROBERTS, M.SC., PH.D., Honorary Lecturer

L. T. COTTON, M.CH., F.R.c.s., Consultant Surgeon and Director of Department
}

\section{Patients and Method}

Patients of both sexes aged 40 and over who were undergoing surgical operations lasting more than 30 minutes were randomly selected and asked for their co-operation and written consent. Those who had clinical signs of recent thrombosis or who were having leg, thyroid, or vascular surgery were excluded.

The ${ }^{125}$ I-fibrinogen was prepared by the method described by Flanc et al. (1968). The thyroid was blocked with $100 \mathrm{mg}$ of sodium iodide given orally 24 hours before operation and continued daily for four weeks afterwards. An injection of 100 $\mu \mathrm{Ci}$ of ${ }^{125} \mathrm{I}$-fibrinogen was given into an arm vein, and the radioactivity was measured over the legs half an hour later. The counting equipment used was the Pitman model 235 isotope localization monitor (Kakkar et al., 1970), and the legs were scanned according to the method of Flanc et al. (1968). Scanning of the legs began two hours before surgery and was repeated 10 minutes after surgery and each day for three days. The diagnosis of venous thrombosis was made when the postoperative count of radioactivity at any site differed by at least $15 \%$ from (1) the preoperative value, (2) an adjacent measurement point on the same leg, or (3) the same point on the other leg. The diagnosis of thrombosis was confirmed when this difference persisted for more than 24 hours.

Each patient provided his own control-one leg being passively exercised while the other was untouched. The leg to be exercised was previously determined by drawing a card from a pack. This provided a random selection of the experimental and control legs and ensured a similar number of right and left legs. The diathermy plate was attached to either leg in a completely random fashion.

The foot mover used to produce continuous per-operative dorsiplantar flexion of the foot has been described elsewhere (Roberts et al., 1971). The foot mover was set to produce dorsiplantar flexion of one leg at a rate of 50 cycles per minute and with an amplitude of $\pm 20^{\circ}$ about the vertical.

\section{Statistical Design of the Trial}

The incidence of postoperative thrombosis in patients aged 40 or more is $20-30 \%$ (Negus et al., 1969; Kakkar et al., 1970). Thus a restricted sequential analysis with $2 x=0.05,1-\beta=$ $0.95, \theta_{1}=0.85$ was designed which gives a probability of $5 \%$. The trial was concluded when the sequentially plotted results passed beyond the chosen upper boundary. Only cases of unilateral thrombosis were used in the sequential analysis, bilateral thrombosis of both the experimental and control legs being excluded.

\section{Results}

Forty-seven patients were required to reach the line of $5 \%$ significance on the sequential analysis (see Chart). The age of the patients ranged from 40 to 84 years, with a mean of 61.7 years for those who developed thrombosis. Thrombosis in the control (unpedalled) leg alone was found in 11 cases and in the pedalled (expcrimental) leg alone in one case. There were also two bilateral cases. The incidence of thrombosis in this 


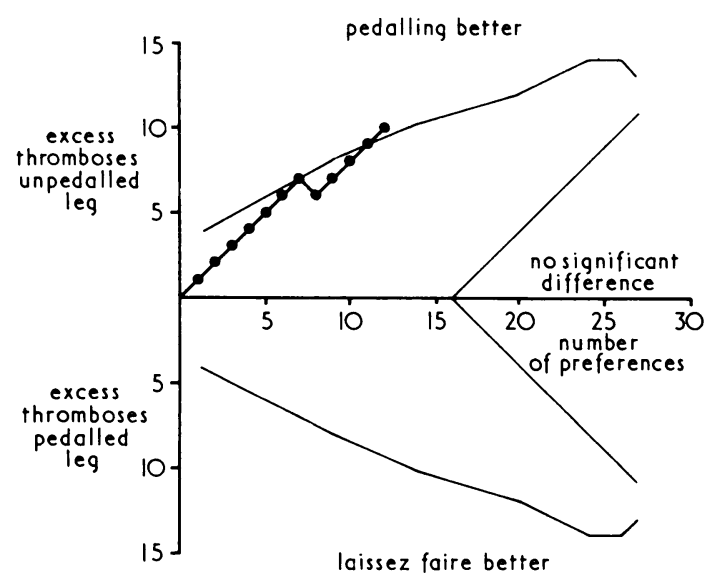

Sequential analysis used in this trial. The line of significance corresponds to a probability level of $5 \%$.

series of 47 patients was $29.8 \%$. The duration of operation ranged from 30 to 200 minutes, with an average of 62 minutes for those who did not develop thrombosis, and 66 minutes for those who did. All patients were seen by the hospital physiotherapists and had routine leg and breathing exercises.

The total incidence of thrombosis in the pedalled (experimental) leg was $3(6.4 \%)$ and in the control legs $13(27.6 \%)$. Therefore per-operative passive dorsiplantar flexion of the foot results in a reduction of $21.2 \%$ (absolute) or $77 \%$ (relative) in the incidence (per leg) of thrombosis. The one thrombosis which appeared in the pedalled leg alone did so on the third postoperative day. Those which appeared in the unpedalled leg were two in the immediate postoperative period, two on the first day, three on the second day, and four on the third day. The two bilateral cases appeared on the third day.

\section{Discussion}

The coexistence of thrombosis and stasis in the soleal sinuses of surgical patients (Gibbs, 1957; Roberts, 1963; Cotton and Clark, 1965) led to the assumption that stasis and/or the associating diminution of pulsatility of venous flow may be an initiating factor for the subsequent thrombosis. Accordingly it was suggested that exercise of the calf muscles was necessary to eliminate the stasis in the soleal sinuses (Gibbs, 1959). An ergometer which was intended to act as a postoperative foot exerciser was designed by Gibbs (1959). The diminution of both the mean value and the pulsatility of venous flow in the per-operative period (Clark and Cotton, 1968) seems to initiate the formation of thrombosis while the operation is still in progress (Flanc et al., 1968) or shortly afterwards.

In the series reported by Browse and Negus (1970) $80 \%$ of the cases were detected in the first three postoperative days, whereas the other $20 \%$ occurred during the fourth to sixth days. Most of the cases of thrombosis which are initiated by venous stasis in the per-operative or postoperative period are expected to appear by the third day, by which time most surgical patients will be ambulant. Venous thrombosis which appears after the third day may well be initiated by increased platelet adhesiveness, which Dhall et al. (1968) showed reached its maximum on the third postoperative day.

In order to assess the efficacy of per-operative pedalling of the foot with the foot mover, it was felt that scanning of the legs in the immediate postoperative period followed thereafter for three days was necessary. Such passive dorsiplantar flexion of the leg can result in an increase of up to $60 \%$ in the femoral arterial and venous blood flow (see above) as well as a tenfold increase in the pulsatility of venous flow (Roberts et al., 1971). It therefore seems that the resultant per-operative haemodynamic changes can reduce the incidence of early postoperative venous thrombosis.

The precise mechanism by which this is achieved remains unknown, and further work, to investigate whether it is the increase in the mean level or the pulsatility of venous flow that is of prime importance, is in progress.

We are indebted to the Wates Foundation for generously providing the financial support for this work. Help in conducting the trial was given by Mr. R. F. Higgins, Dr. D. Tolley, and Mr. J. Prior, and we would also thank Mr. M. Clarke, of the medical physics department for labelling the fibrinogen.

\section{References}

Atkins, P., and Hawkins, L. A. (1965). Lancet, 2, 1217.

Browse, N. L., and Negus, D. (1970). British Medical fournal, 3, 615.

Cotton, L. T., and Clark, C. (1965). Annals of the Royal College of Surgeons of England, 36, 214.

Dhall, D. P., Bennett, P. N., and Matheson, N. A. (1968). Acta Chirurgica Scandinavica, Suppl. No. 387 , p. 75.

Flanc, C., Kakkar, V. V., and Clarke, M. B. (1968). British fournal of Surgery, 55, 742.

Gibbs, N. M. (1957). British fournal of Surgery, 45, 209.

Gibbs, N. M. (1959). British Ұournal of Surgery, 47, 282. Kakkar, V. V., Nicolaides, A. N., Renney, J. T. G., Friend, J. R., and
Clarke, M. B. (1970). Lancet, 1, 540.

Negus, D., Pinto, D. J., and Brown, N. (1969). Acta Chirurgica Belgica, 68, 507.

Roberts, G. H. (1963). Scottish Medical fournal, 8, 11.

Roberts, V. C., Sabri, S., Pietroni, M. C., Gurewich, V., and Cotton, L. T. (1971). British Medical fournal, 3, 78 .

Sabri, S., Roberts, V. C., and Cotton, L. T. (1971). In press.

Virchow, R. (1856). Gesammelte Abhandlungen zur Wissenschaftlischen Medicine, p. 227. Frankfurt, Meidinger Sohn. 